Trinity University

Digital Commons @ Trinity

Sociology \& Anthropology Faculty Research

Sociology and Anthropology Department

$1-1995$

\title{
The Political Economy of Responsibility in Health and IIIness
}

John Donahue

Trinity University, jdonahue@trinity.edu

Meredith B. McGuire

Trinity University, mmcguire@trinity.edu

Follow this and additional works at: https://digitalcommons.trinity.edu/socanthro_faculty

Part of the Anthropology Commons, and the Sociology Commons

\section{Repository Citation}

Donahue, J. M., \& McGuire, M. B. (1995). The political economy of responsibility in health and illness. Social Science \& Medicine, 40(1), 47-53. doi: 10.1016/0277-9536(94)00126-E

This Article is brought to you for free and open access by the Sociology and Anthropology Department at Digital Commons @ Trinity. It has been accepted for inclusion in Sociology \& Anthropology Faculty Research by an authorized administrator of Digital Commons @ Trinity. For more information, please contact jcostanz@trinity.edu. 


\title{
THE POLITICAL ECONOMY OF RESPONSIBILITY IN HEALTH AND ILLNESS
}

\author{
John M. Donahue and Meredith B. MCGuire \\ Department of Sociology and Anthropology, Trinity University, San Antonio, TX 78212, U.S.A.
}

\begin{abstract}
This article addresses the question; to what extent do health care strategies in a given political aconomy increase people's perceptions of responsibility to take charge of their health, but do not structurally empower them to satisfy their health needs. In shaping health care policies, societies typically adopt one of three broad strategies, linking their larger political economy and modes of exercising power: a marketplace strategy, a state-managerial strategy or a national participatory strategy. Because of their different arrangements of structural power, these strategies result in three very different approaches to responsibility for health and illness. Changes in the political economy of health in Nicaragua during the Somoza, Sandinista and Chamorro periods illustrate the changing fields of choice within which caro-seekers must make their health care decisions.
\end{abstract}

Key words-politics, health responsibility, Nicaragua

The question of individual accountability in health and illness can be phrased in scveral ways. One might ask to what extent the burden of 'guilt' or 'blame' should be placed on the individual or on the social environment in which people find themselves? Modical sociologists and anthropologists typically approach this theme by analyzing health-seeking processes and the social etiology of disease. In order to address the policy implications of this theme, however, a political economy of health and illness provides a useful perspective for our discussion of accountability and responsibility. How might an analysis of power and its exercise within the arena of health and illness help us to understand, first, how responsibility is defined and exercised, and then how shame and guilt for illness are assigned? Specifically, we suggest that the political economy in which a health system operates strongly inftuences people's perceptions of responsibility for their health, but may not structurally empower them to satisfy their health needs.

\section{STRUCTURAI. POWER AND THE EXERCISE OF RESPONSIBILITY}

In his Distinguished Lecture, Eric Wolf [1] describes four modes of the exercise of power, all of which, we argue, can be found within any political oconomy. The first three are the individual, the social and the tactical; they describe power as interactional. Individual power refers to a person's ability or capacity to influence the play of power. Social or dyadic power is displayed in the attempts of one person to exert control over or influence another. Organizational or tactical power applies when an actor in one field of activity is able to restrain the activity of an actor in another setting.

The fourth mode of power, structural power, is less visible because it is not directly observed in the field of interpersonal relations. According to Wolf [1, p. 587], structural power is the ability to deploy and allocate labor in a social field in such a way as "to render some kinds of behavior possible, while making others less possible or impossible." Structural power varies according to political economy; the exercise of that structural power, in turn, affects the exercise of the three interactional modes of power. These differences in structural power profoundly influence each society's allocation of responsibility for health and illness.

The exercise of structural power is often less overt and more difficult to discern (and, thus, to contest) than interpersonal power, because it is so subtly embedded in a social structure. Social control exercised in the mode of social power, for example, might be observed in police crowd-control or corporate promotions and firing-i.e. situations where the actions and opposing interests of actors are relatively identifiable. By contrast, structural power often manifests itself in getting actors to self-constrain and self-limit, for example by controlling the terms of discourse. Thus, in the case of health and health care, structural power may dictate: You must watch yourself to see that you control your body and emotions to conform to our norms; we will specify how you may conceptualize health and health care in articulating your needs.

Similarly, masked by seemingly neutral technologies, structural power can be more far-reaching than interpersonal tactical power. Implicit in each 
technology are important political outcomes, such as whether it promotes centralization of decisionmaking and control, inequality, hierarchy and domination, vast scale of organization, or sacrifice of civil liberties. Technologies include both organizational and mechanical arrangements. The decision to invest in high-tech mechanical technologies, thus, carries implicit political outcomes for their management. Similarly, certain organizational technologies (such as the medical referral system) will tend to reproduce a hierarchical structure, such as patron-clientism; by contrast, other organizational technologies (such as those involving primary health care and community health workers) tend to encourage local control over health care choices. The exercise of structural power is exemplified by the decision to implement technologies, whereby political implications are glossed over by the representation that the choice was made on purely technical-rational grounds [2].

In shaping health care policies, societies typically adopt one of three broad strategies, linking their larger political economy and modes of exercising power. The marketplace strategy emphasizes individual behavior as consumers in a medical marketplace of goods and services. The role of the state is theoretically limited to keeping the marketplace open and active. Considerable professional and corporate marketplace control, however, greatly constrains the actual freedom for individual choice in the medical marketplace. The state-managerial strategy, by contrast, removes the health-related issues from the marketplace, but emphasizes professional and/or state-bureaucratic managesial control over most areas of health decisionmaking and allocation of programmatic resources. A third approach, the national participatory strategy retains national level policy efforts and economic support for health programs, but emphasizes broad individual and community participation in both decision-making and health promoting actions. Because of their different arrangements of structural power, these strategies result in three very different approaches to individual responsibility for health and illness.

\section{THE FIELD OF HEALTH CHOICES IN A HEALTH MARKETPLACE}

In the United States, for example, the structural power of corporate and medical professional interests results in individual responsibility for health being defined in terms of consumer and life-style behavior. The 'responsible' person, thus, is one who buys sufficient health insurance, consumes the right diet and avoids consuming the wrong products, purchases health professional care wisely, takes prescribed medications and complies with other 'doctorsorders,' spends stress-reducing vacations, and invests in a good health spa. The commodification of health, fitness and beauty directly serves the interests of powerful actors in the capitalist marketplace. By shifting the major portion of responsibility for health to the individual and defining that responsibility in terms of consumer behavior, this system reduces its attention to corporate or state responsibilities for people's health or illness.

The biomedical paradigm itself contributes to the emphasis on individualistic, rather than social or political, approaches to disease. The biomedical paradigm treats disease as a leature or property of the patient, as if disease were an objective 'thing' which the patient 'has' [3]. For example, if work in a chemical factory creates health risks for workers, the location of disease as a property of individual bodies leads to an emphasis on finding which individuals are more likely to 'react' to workplace toxins. Accordingly, the corporate responsibility is reduced to counselling individuals 'at risk' to change positions, rather than to reducing the exposure of all workers or eliminating certain industrial processes that require use of toxic substances. The biomedical model transforms occupational disease into a thing that befalls some individuals, rather than viewing it as the result of human decisions made by real people (even if in the guise of corporate actors) affecting their own or others' health.

The emphasis upon disease as an object that occurs within an individual, produces the tendency to locate responsibility for illness in the individual, often resulting in blaming the victim. The sick person is assumed to be responsible for having taken health risks, such as accepting a hazardous job, failing to use seat-belts, or moving to an area with polluted water. The individual is held accountable for unhealthy lifestyle choices, such as smoking, drinking, poor eating habits or lack of exercise, as well as for illness-producing emotional styles and characteristic responses to stress [4]. Such emphasis upon the individual's responsibility for illness often results in inattention to the sick person's whole situation. For example, one study of doctor-patient communication noted the extent to which the patient's larger social predicament (such as an extremely stressful workplace) was generally ignored or reduced to individualistic treatments, such as recommendation of tranquilizers or a vacation [S].

Similarly, health care workers often attach considerable blame to a patient's non-compliance with doctors' 'orders' (note the power differential implied in this concept). In many cases, assignment of responsibility to the patient does not take into account any of the situational factors that would make a real difference in whether the sick person is enabled to comply. For example, if the therapeutic regimen for an obese hypertensive woman, who is holding down two jobs to support her mother and three teenage children, fails to take into account the very rea! limitations of her daily life, it is merely shift. ing responsibility - and blame for inevitable failure to comply - to her, on top of all her other burdens [6]. Nevertheless, the U.S. policy strategy of focusing on 
individual responsibility for health and illness meshes conveniently with other cultural ideals, especially the emphasis on individual control and self-discipline in lifestyle behaviors [7].

Instead of examining the conditions of work that create stress, the medical model radically changes the field of choices for reducing stress. Instead of looking at the marriage, family and work pressures of a compulsive overeater or smoker, emphasis is upon individual willpower to control personal behavior. A medical model which locates illness as a property of the sick individual contributes to the one-sided assignment of responsibility to that individual, without promoting any of the social or environmental changes which would empower the individual to prevent illness or get well. Because this individualistic definition of responsibility is embedded in the cultural package of Western medicine, it may also inadvertently inform state-managerial and participatory strategies.

\section{STRUCTURAE POWER IN THE} STATE-MANAGERIAL APPROACH

Historically in most capitalist and socialist countries, working class organizations have been able to successfully promote the establishment of a national health system [8]. Thus, health ceases to be a privilege of the well-to-do and is defined as a citizen right, much like public education. Acordingly, responsibility for health resides with the individual, but the state assumes the financial liability. One might conclude that responsibility for health, both individual and collective, would be greater in a society in which it was defined as a right rather than as a commodity. In fact, Cereseto and Waitzkin's exhaustive study of World Bank data led them to conclude that "socialist countries generally have achieved more favorable PQL [Physical Quality of Life] outcomes than capitalist countries at equivalent levels of economic development" [9]. This reallocation of economic resources does not, however, insure a reallocation of power.

Navarro concludes that the former U.S.S.R. did not really have a socialized health system [10]. Rather, the Soviet health system was ultimately in the control of a managerial bureaucracy that denied direct input from the community. For example, while doctors treated victims of the nuclear disaster at Chernobyl, the state bureaucracy refused to disclose important information about the extensive health risks to affected citizens living in the immediate region. The exercise of bureaucratic power in such a state system does not promote either individual or collective responsibility for health.

\section{STRUCTURAL POWER IN THE NATIONAL} PARTICIPATORY STRATEGY

Ideally a health care system would promote individual and collective responsibility for health care and provide citizens with the necessary means with which to satisfy their health needs, both preventive and curative. While some health care systems approximate this ideal, marketplace or state-managetial approaches tend to restrict people's control over the means of health production. For a health care system to be participatory and democratic, a reallocation of structural power would need to occur. Following Segall, we argue that any health system opting for a more egalitarian health care strategy would have the following characteristics:

(1) emphasis on the social etiology of disease and efforts to enhance health through a more equal access to goods and services;

(2) programmatic eflorts to encourage participation in and organization of health-related activities; and

(3) empowerment of the people to take economic and political control of health services out of the exclusive domain of professionals [11].

\section{THE STRCGGLE FOR STRUCTURAL POWER IN NICARAGUA: A CASE STUDY}

Nationalized health systems are more egalitarian than systems predicated upon each individual's ability to pay. Nevertheless, structural power is often in the hands of the health bureaucracy. The state apparatus for administering a nationalized health system may itself structure the field of health choices for its citizens. Navarro argues that the configuration of power relations in a health system results from the interplay of two forces [10, p. 115]. The one, a centripetal force, moves the health system toward the political centralization of power by dominant groups, be they classes or status groups such as bureaucrats. The other, a centrifugal force, is determinod by the democratization and the decentralization of the system. In turn, this democratizing force engenders other centrifugal forces such as deprofessionalization, despecialization and an emphasis on primary health care in rural communities. The Nicaraguan health system under Somoza, the Sandinistas and the current Chamorro government oflers a case study that illustrates the interplay of these two forces at work to define the structural field of choice within several organizational strategies.

The main features of the public health system under the Somoza government were top-down control, fragmentation and generalized neglect [12]. The primary organizational strategy was patron-clientism [13]. The dictator exercised vertical control through 23 autonomous health institutions which became channels for the distribution of favors in exchange for political loyalty. The result was a health delivery system whose resources went primarily to the cities, especially Managua. For example, in 1974 the Ministry of Health budget accounted for only $16 \%$ of health sector expenditures (excluding the water and sewer agency). Nearly $75 \%$ of the budget was spent in 
Managua which accounted for only $25 \%$ of the entire population in that year [14]. The effect of this exercise of structural power was to leave the vast majority of Nicaraguans, especially those in rural areas, to exercise their health choices with the meager resources that were available in the private or traditional health sectors.

With the ascendancy of the Sandinistas in 1979, there emerged a policy to reallocate national resources according to the logic of the majority.' An effort was made to initiate a series of reforms in the industrial, agrarian and social welfare sectors that would give preference to the needs of the poorest sectors of the society, principally in the neglected rural areas. The agrarian reform and the literacy campaign were early examples of this exercise of structural power. A similar effort was made in the health sector and illustrates the fundamental feature of the new structure of power. Popular participation was to replace old patron-clientism. New horizontal structures were created at the community level to challenge the dictator's vertical channels of patronage. In addition, these popular organizations challenged the patron-clientism that the physician-dominated health bureaucracy continued to reproduce.

In 1980 a decision was made within the newly created Nicaraguan National Unified Health System (SNUS) to institutionalize popular participation in the planning and implementation of health care delivery $[12,15]$. The organization within the Ministry of Health that was charged with this task was the Division of Communication and Popular Education in Health (DECOPS). The organizational structure of participation included the creation of popular health councils ('consejos populares de salud', CPSs) at local, regional and national levels. Several voluntary associations, called mass organizations ('organizaciones de masas'), participated in health planning and delivery. The Division of Communication and Popular Education in Health had originally intended the health councils to be made up exclusively of the popular organizations. They could thereby better negotiate community health concerns and strategies with the Ministry as a partner in planning. With the emergence of the mass drug administration programs ("popular health days') in 1981, however. the health councils became a joint body of rept sentatives from the popular organizations and the Ministry. The effect was to subordinate the health councils to the centralized planning of the Ministry while the popular organizations were more involved in staging the health work days [16]. The mass drug administration programs became arenas in which the popular health councils and health promoters first challenged the efforts of professionals to define the field of choices [15]. These attempts were met with resistance from many volunteers and health educators. The stage was set for further tests between professionals and community people on the field of choice within which the Popular Health Councils were to work.
After the first national mass drug administration programs of 1981 and 1982, the Popular Health Councils turned their attention to the exercise of some control over health institutions and health personnel. For the purposes of the present discussion, these efforts can be understood as attempts to 'restructure the field of choices.' The meetings of several health councils in northern Nicaragua reveal the range of challenges to professional control which the Popular Health Councils, as a participatory strategy, allowed to surface, and to be acted upon. The new field of choice included the supervision and evaluation of medical personnel in the area clinics and hospitals.

The Popular Health Council requested that the Ministry advise it when evaluations were to be held. It stipulated that health personnel should be evaluated on their performance in the areas of preventive medicine and popular education. One area clinic was singled out for specific criticisms. Members pointed out that physicians were not keeping their hours in the area clinic of El Carmen and patients were often treated condescendingly. To provide for more accountability in provider-patient relationships, the Health Council agreed to recommend that all health personnel wear a name tag for easier identification. Another complaint was that some people had to wait in line while others were allowed to go forward because of favoritism ('el amiguismo'). Members of the Health Council asked that the clinic look for more efficient ways to handle the patient load. They recommended increased use of volunteers in clerical tasks.

Another struggle for structural power centered on the use of local folk healers. The Popular Health Council of the rural district of Rio Viejo in Northern Nicaragua had asked the Regional Office of the Ministry to assign the local folk healer to their newly constructed health post. At about the same time, the Ministry of Health had ordered a folk healer in another village to stop practicing medicine there. The people from that village had written to La Barricada, the national newspaper of the Sandinista Party, and complained. The Departmental Health Council responded by commissioning the Women's Association to take a census of all practitioners of folk medicine ('los recursos empiricos') in the Department. These events seem to have precipitated a special meeting of the Popular Organizations and the Ministry in the county seat of El Arroyo on 12 April, 1982. The objective of the meeting was to formulate a general policy towards folk healers.

The discussion revealed that the community held quite different opinions of the social and cultural authority of folk healers compared with the physician in the local clinic. The participants offered what amounted to common complaints against the professional practitioners of medicine in rural areas. The folk healer is available day and night; the physician only during the day.... The healer makes home visits, while the physician never moves from the clinic.... 
The healer is a confidante and gives emotional support to the patient... . The folk healer's practice of modicine is more in accord with the beliefs and expectations of the people.... The healer shares his/her knowledge, but the doctor does not explain or educate one to the nature of the illness or the reason for the treatment.... The people can tell the difference between the illnesses which healers can treat and those they cannot, but people often go only to them because professional health services are not available.... The meeting had the effect of forestalling further action against the folk healers by the Ministry.

The structural power of medical patron-clientism in many developing capitalist and socialist countries is often represented in two organizational schema, that of the administrative hierarchy of the Ministry and that of the referral system. What is different in the Nicaraguan case is that the Ministry of Health constituted yet a third structure influencing the decisionmaking process. The Popular Health Councils at local, regional and national levels act as a 'lever' which can be used to move the administrative 'pyramid' and the referral 'octopus' to function in an arena larger than what their particular bureaucratic or professional interests might dictate.

The Community Health Workers, likewise, had institutional advocates within the Ministry of Health at both national and regional levels in the Division of Communication and Popular Education in Health. That Division was made up of health educators whose activities, while coordinated with the other Divisions within the Ministry, were less under the control of the medical profession. The result was a healthy tension between professional and popular health agendas, or to use Navarro's terms, between 'centripetal' and 'centrifugal' forces within the health care system [10, p. 115]. The Division of Communication and Popular Education in Health, along with the Popular Health Councils and local Health Educators sought to maintain that dialectic in Nicaragua. The increasing pressures of the Contra war gradually shifted the health priorities fiom preventive back to curative care. As rural violence curtailed outreach efforts, the clinics and hospitals again became the locus of most health care. To the extent that these institutions are dominated by medical professionals, the field of choices open to popular health organizations were again constrained by these 'centripetal' forces. Compounding the situation was a large exodus of physicians from the country because of the United States' embargo and the demands of the war.

The electoral victory of the Chamorro government in 1990 ushered in a new configuration of structural power in the health sector. While there was no direct repeal of Sandinista health policy, there has been a general reduction of services for several reasons. In an effort to reduce government spending and conform to IMF loan conditions, the Chamorro government offered a generous 'once and for all' cash award to public employees who resigned their jobs. Many health workers, frustrated by the lack of medical supplies and medicines, have chosen to leave the health sector. The Ministry of Health reduced its hours of operation to between 8 a.m. and 1 p.m. Physicians carry on their private practice in the afternoons. In effect, there has been a generalized slowdown in public health activity, and a decided shift to private sector medicine. There has been an increase in health activities among non-governmental organizations such as Movimiento Comunal, but PVOs operate with fewer resources than does the Ministry of Health.

Needless to say, the field of health choices for many Nicaraguans, already limited by the military and conomic effects of the contra war, have not improved noticeably since the war ended and the embargo lifted. Now, however, the field of choices are being defined by the demands of bi-lateral and multilateral lending agencies, such as USAID and the IMF. The 'logic of the majority' has been replaced by the 'logic of the bankers.' To that extent Nicaraguans must face the professional dominance of financiers, as well as physicians. In the political economy of health structural power is exercised not only among nationa! status groups such as medical professionals, but also by actors in the international arena. Even though medical professionals might argue against economic retrenchment and for an increase in expenditures in the health sector, their assertion of professional power would still effectively limit the field of choices open to care-seekers.

\section{PROFESSIONAL DOMINANCE OF THE FIELD OF HEALTH CHOICES}

Professional dominance may be found in any political cconomy partly because it is a byproduct of the rationalization of Western medicine. Starr [17] notes that physicians have exercised cultural and social authority in Western medicine. Their cultural authority is seen in the ability to define the meaning of health and illness. To the extent that patients accept these cultural and ideological meanings, they are disposed to follow the doctor's orders (social authority) and to believe that the doctor is the appropriate source of help to seek.

The fact that medicine and other health services have become increasingly specialized and linked with control over specialized skills and knowledge, means that all health care systems must deal with the assertion of professional dominance. In a 'free' health market economy, the professionalization of medicine represents, in Larson's terms, a sociopolitical movement organized to achieve a 'monopoly of opportunities in a market of services or labor and, inseparably, monopoly of status and work privileges' [18]. Statemanagerial approaches may constrain or eliminate the market dynamics, but professionals often still 
exert their relative power to obtain status, financial and work privileges.

In a society employing a participatory strategy, the balance of power between professionals and laypersons is a fine line that must be continually negotiated and defended in order to maintain high levels of involvement of both professionals and laypersons. Each new decision, such as whether to spend money on a piece of diagnostic equipment or on a nutrition-education program, becomes the focus for exertions of power and authority. By definition, national participatory strategies are aimed at maximizing widespread involvement of lay individuals and groups, who at the same time are necessarily lacking technical or professional expertise and, thus, susceptible to deferring to professional authority.

One of the key results of such societal deference to medical authority is that medical professionals are granted enormous power to define health and illness - that is, to define what areas of life 'ought' to come under their domination. For example, in many modern societies, we have witnessed in just a few decades the extensive medicalization of childbirth, menopause, child-rearing, virtually all forms of deviance (such as alcoholism, promiscuity, and child abuse), weight-maintenance, old age and dying [19].

The implications of professionalization and medicalization for the allocation of responsibility and blame are, first, that they create the model of the medical professional as authoritative, powerful and active, while the health care recipient is passive, obedient and weak [20]. This dominance-dependence relationship is often embodied in policy and organizational structures, such as the organization of hospitals and clinics. Second, to protect or to extend their dominance, professionals and organizations often maintain tight control over the knowledge or expertise which would enable laypersons to make informed choices.

Third, professionalization and medicalization produce the expectation that the sick person (or family of the sick person) ought to seek professional help for all medicalized 'problems' and to comply with all 'orders' from that authoritative professional. Neverthless, many physicians complain that patients consult them for unimportant reasons; they also complain that patients lack humility to accept medical experts' judgment [21]. The contradictory norm, then, is that laypersons should be actively expert in judging correctly which ailments to refer to the professional, and then assume a humbly passive role when under the care of the professional.

Professionalization and medicalization result in blame being allocated not only for getting sick, but also for not seeking professional help soon enough, for not seeking the proper professional care and for not doing whatever that professional says to do. Indeed, some U.S. courts have prosecuted parents for failing to meet these responsibilities.

Professionalization and medicalization processes, thus, promote dependency of the sick person upon profession experts, while simultaneously deflecting much responsibility from the professional to the health-care seeker. Social policies and organizational structures which perpetuate or extend these powerful sources of dependency and dominance make individuals responsible without giving them the effective power and sense of agency to accomplish society's expectations.

\section{CONCLUSION}

We can now return to our original question: To what extent do health care strategies in a given political economy increase people's perceptions of responsibility to take charge of their health, but do not structurally empower them to satisfy their health needs?

Responsibility in the health marketplace is placed squarely on the individual. In an interview Dr Louis Sullivan, Former Secretary of Health and Human Services, asked Americans to make their health "a national obsession' [22]. "Each American," he said, "must accept personal responsibility for better health behavior and practices." This assertion was followed by a litany of behaviors that such responsibility implied: stopping smoking, adopting good eating and drinking habits, getting vaccinations, and wearing seat belts. No mention was made of the social and economic obstacles that limit health choices for most Americans. No recognition was given to the corporate or bureaucratic structures that actually contribute to illness and poor health among many Americans.

Both personal and social responsibility are exercised within the state-managerial strategy. The responsibility for the cost of the health care is shared more equitably among the citizenry. Nevertheless, the field of choices can still be bounded by professional and bureaucratic dominance. As nation-states, such as Nicaragua, attempt to move to more participatory forms of health care, physicians, health administrators and citizens will need to delinate anew the field of choice in which personal and public responsibility for health is exercised.

\section{REFERENCES}

1. Wolf E. Distinguished lecture: lacing power-old insights, new questions. Am. Anthrop. 92, 584, 1990.

2. Winner L. The Whate and the Reactor: A Search for Limiss in an Age of High Technology. pp. 19-39. University of Chicago Press, Chicago, 1986.

3. Taussig M. T. Reification and the consciousness of the patient. Soc. Sci. Med. 14B, 3, 1980.

4. Crawlord R. You ase dangerous to your health: the ideology and politics of victim blaming. Int. J. Hlth Serv. 7, 663, 1977.

5. Waitzkin H. B. The micropolitics of medicine: a contextual analysis. Ins. J. Hlih Sero. 14, 339, 1984.

6. Kleinman A. The Illness Narratives: Suffering. Healing. and the Human Condition. Basic Books, New York. 1988. 
7. Taylor R. The policies of prevention. Soc. Policy 13, 32. 1982.

8. Navarro V. Why some countries have national health insurance, others have national health services, and the United States has neither. Soc. Sci. Med. 28, 887, 1989.

9. Cereseto S. and Waitzkin H. Capitatism, socialism and the physical quality of life. Med. Anthrop. CrossCullural Studies Hlith Iliness 11, ISI, 1989.

10. Navarro V. Social Security and Medicine in the USSR: A Marxis! Critique. Lexington Books, Lexington, MA, 1977.

II. Segall M. On the concept of a socialist health system: a question of Marxist epistemology. Int. J. Hlih Serv. 13, 221, 1983.

12. Donahue J. M. The Nicaraguan Revolution in Healih: From Somoza to the Sandinistas, pp. 9-20. Bergin and Gar vey, South Hadley, MA. 1986. Data sources include interviews of participants and minutes of four meetings of two Departmental level CPS. The meetings were held between April and August of 1982. A fifth meeting on folk healers which took place on 2 April 1982 was between MINSA officials and representatives of the Popular Organizations. The place names have been changed to maintain anonymity.

13. Gamer R. The Developing Nations: A Comparative
Perspectine, pp. 103-108. Boston, Allyn and Bacon. 1982.

14. United States Agency for International Development (USAID). Healih Sector Assessment for Nicaragua. Managua, pp. 46, 8I, 1976.

15. Donahue J. M. The politics of health care in Nicaragua before and after the revolution of 1979. Human Organ. 42, 264, 1983.

16. Keyzer B. de and Ulate J. Educacion. Participacion en salud e ideologia: Nicaragua pasado y presente. Revisio Centroamericana de Ciencias de las Salud 19, 1981.

17. Starr P. The Social Transformation of American Medicine. Basic Books, New York, 1982.

18. Larson M. S. Professionalism: rise and fall. $I n t$. J. Hlth Serv. 9, 607, 1979.

19. Conrad P. and Schneider J. W. Deviance and Medical. ization: From Badness 10 Sickness. C. V. Mosby, St Louis, 1980.

20. Chrismas N. J. The health seeking process: an approach to the natural history of illness. Culture, Med. Psychiat. 1, 351, 1977.

21. Cartwright A. Patients and Their Doctors. Atherton, New York, 1967.

22. Millenson M. L. 'Get obsessed with helath, U.S. told.' Chicago Tribune, October 24, 1989. 